\title{
Lithological features of Vistula River channel deposits in the light of micromorphological analysis
}

\author{
Marta Bielawska \\ Institute of Geoecology and Geoinformation, Adam Mickiewicz University in Poznań, Poland; mbiel@amu.edu.pl
}

\begin{abstract}
The aim of the study was to identify and assess the lithological features typical for alluvial sediments of Vistula River from the natural part of its course on $603 \mathrm{~km}$ of the river course. For this purpose, the micromorphological analysis was carried out for a sample taken from the surface of a tree covered island. The analysis is laborious, but its great advantage is that it allows to determine the detailed characteristics of undisturbed sediments, supplying other lithological studies. Examined thin section showed fractionation lamination within medium and fine sands, interbedded with coarser grains with some organic admixtures. Detailed analysis allows to detect gradual and sudden changes of discharge energy.
\end{abstract}

Key words: micromorphology, alluvial sediments, Vistula River, central Poland

\section{Introduction}

Micromorphological analyses are among rarely used in sedimentology of loose deposits because of complicated and time-consuming process of samples preparation in the form of thin sections used for microscopic examination. Proper process of preparation allows the description and interpretation of components, structures and features of sediments of different age and genesis. The biggest advantage of micromorphological method is the possibility to observe undisturbed sediments in an enlargement, to assess their character and deposition conditions. Aside of description of typical morphological features as shape, size, sphericity or roundness index of particles, surface morphology, weathering degree of minerals, illuvial movement of colloidal clay, mineral and chemical composition, iron or calcium carbonate concentrations, physical changes (frost, compactional etc.) and the deformations can be also pointed out (Konecka-Betley 1996, Kemp 1998). It is also possible to determine how separate components correlate in effect of internal and external stresses as well as due to syn- and post-depositional processes (Menzies et al. 2010).

The aim of the paper is to attempt the determination and assessment of lithological features characteristic for Vistula River channel alluvia and synthesis of results obtained both with macroscopic and laborious micromorphological analyses, the latter giving an advantage of undisturbed sediments observations.

\section{Methods}

Micromorphological investigations were initiated by $\mathrm{Ku}$ biena (1938), who described them as a method based on quantitative and qualitative analysis of soil components, with which the relations between different particles in undisturbed soil can be assessed. The micromorphology definition was more precisely set up during $7^{\text {th }}$ Soil Micromorphology Symposium in 1988 in San Antonio, as the method of examination of undisturbed samples of formations as soils, sediments and unconsolidated rocks, on thin sections, under the microscope in various types of light (Douglas 1988). First methods of micromorphological description proposed by Brewer (1964) were modified by International Soil Sciences Society researchers (Bullock et al. 1985). Currently the most frequently used key used for microstructures visible in thin sections interpretation was elaborated by Stoops (2003). The methods of thin sections preparation depends on procedures within different laboratories. The ones in the current elaboration, used at the AMU Institute of Geoecology and Geoinformation Micromorphology Lab embrace eight stages shown on Fig. 1.

Techniques of sampling differ depending on materials, available equipment, environment and aim of research. Samples for thin sections may be acquired either from outcrops or boreholes. Usually undisturbed sediment samples are collected in the field into the so called " $\mathrm{Ku}$ - 


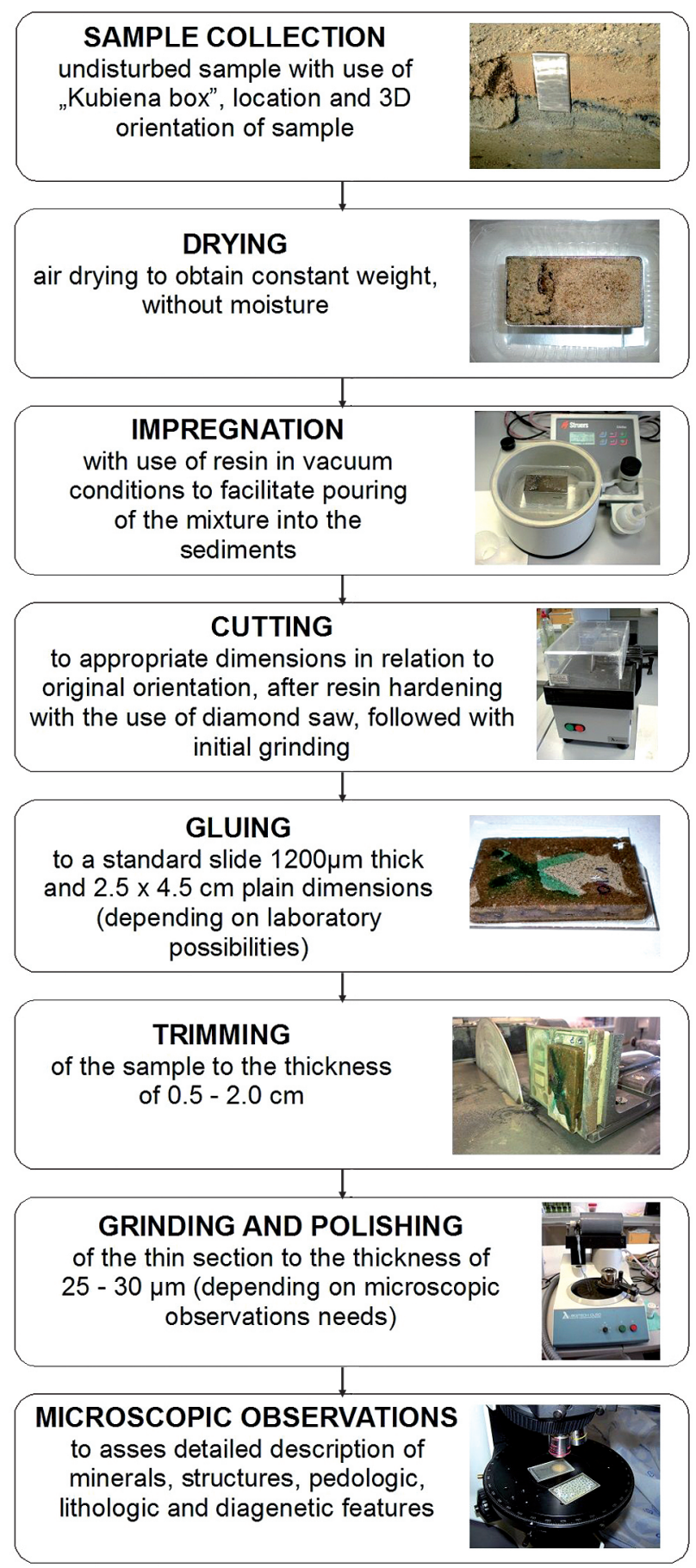

Fig. 1. Micromorphological practice flow chart (acc. Budek 2010, modified)

biena boxes", together with the description of sampling place, geographic and three dimensional orientation and depth. Sampling strategies (Kemp 1985, Palmer et al. 2008) descriptions have to take into consideration the aim of sampling and number of samples needed for the realization of this aim. Samples secured with waterproof coating, well-marked with descriptions again, are transported to the laboratory.

Most technical problems are connected with sediments drying and total water removement. These processes are very slow and can take from 2 to 6 months, depending on sample size and provenience. The sample is thought to be dried when its weight is stabilized. Air drying in room temperature is problematic, because can result in fissuring, However such fissures are detectable, because they differ distinctly from natural ones. There also may be a question, why such fissures originated in the particular place and whether that place is not a kind of "weakness" of sediments. Moreover the fissures helps the resin inclusion, allowing full impregnation (Pusch 1999). If it is needed, the sample before impregnation may be immersed in acetone, that is exchanging with water (Fitzpatrick 1993).

Sample impregnation is done with the use of resin and hardener mixture in a vacuum chamber, to avoid sample cracking and carefully pour without air bubbles, though even the most delicate structures are preserved (Cailleau et al. 2009). Vacuum use is also helping the permeation of resin inside of the sample. In hard samples it is common to color the resin for easier identification of pores and carbonate minerals (Kemp 1985, Murphy 1986, Lee and Kemp 1992, Camuti and McGuire 1999). The sample is left for impregnation and hardening for at least 48 hours the time is depending on resin type. After drying the sample is cut with a diamond saw, to the adequate size, keeping earlier established orientation. The elements, usually 5-8 $\mathrm{mm}$ thick, are grinded to obtain a smooth surface to be glued with a slide. We use a standard slide thickness $1200 \mu \mathrm{m}$ and $2.5 \times 4.5 \mathrm{~cm}$ plain dimensions, however there are also other sizes, like Kubiena $(5 \times 7 \mathrm{~cm})$ and mammoth thin sections $(14 \times 8 \mathrm{~cm})$ (van der Meer and Menzies 2011). Finally, the sample is grinded and polished to the thickness $25-30 \mu \mathrm{m}$, depending however on the actual needs of microscopic observations (Mroczek 2001). The last stage in the micromorphological method is microscopic observation, leading to detailed description of minerals, structures and pedological, sedimentological and diagenetic features. To analyse the thin section images a standard petrographic microscope with 20-50x magnification can be used (Kołodziej 1995), with a supply of polarization microscope with a magnification up to 100x (Carr 2004).

\section{Study site}

Analyses were done with the use of samples collected September 24 2012, taken from the outer part of a tree covered island (5 $\mathrm{cm}$ above the current water level 259 $\mathrm{cm}$ measured at the gauge station Wyszogród), located SW from the town Zakrzewo Kościelne near Kępa Polska (Fig. 2). This part of Vistula River channel $(603 \mathrm{~km}$ of the river course) is a natural one, 800-900 m wide, with characteristic channel bars moving mostly along the eastern channel side of the channel (Fig. 3). The water level tended to lower with the rate of $2 \mathrm{~cm}$ per day at that time, though the exposed sediments surface was assumed to be about 3-4 days old, i.e. right after the process of deposition. 


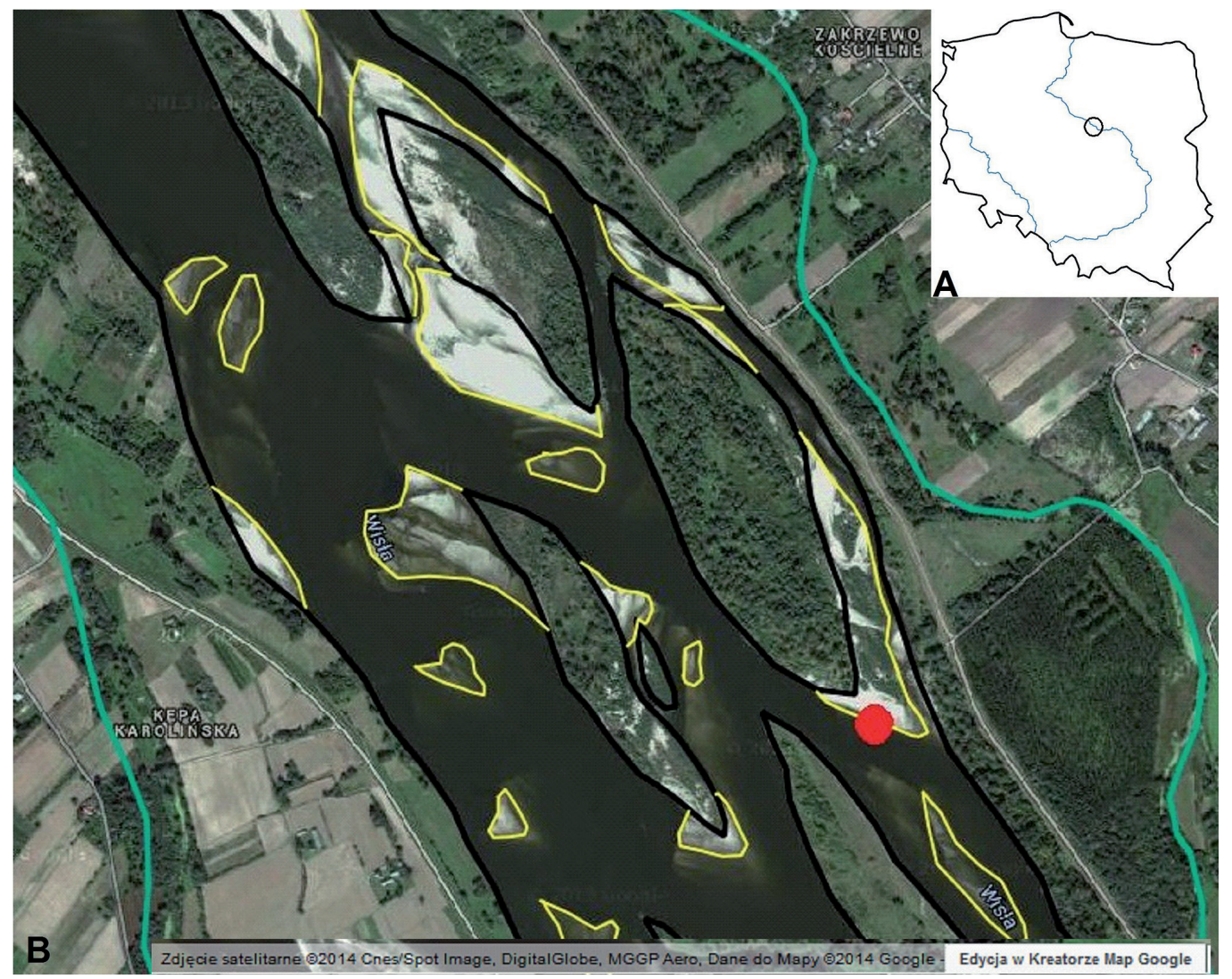

Fig. 2. Study area presented on the map of Poland (A) and sampling site location within Vistula river channel (B)
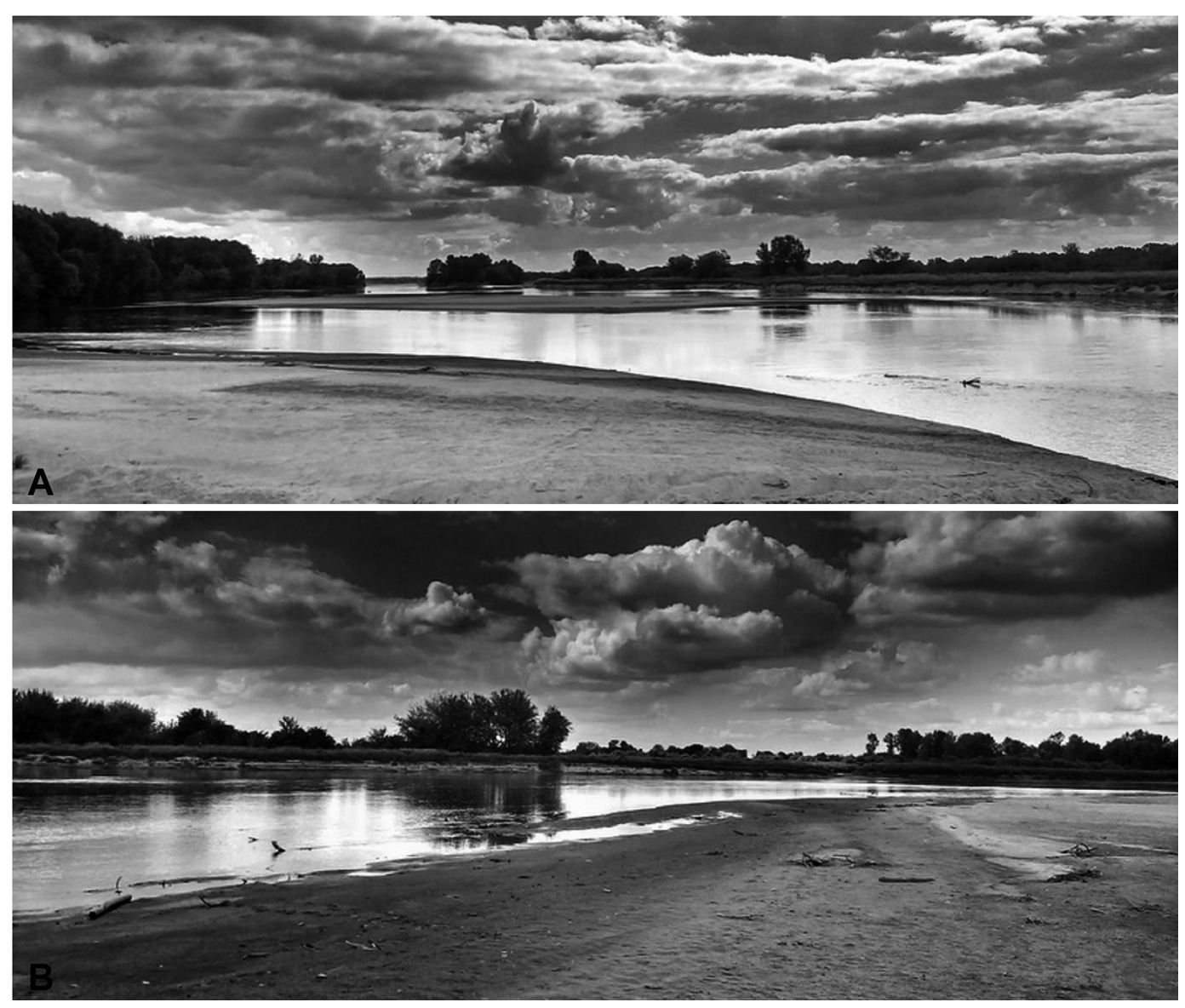

Fig. 3. Analysed area

A - view up river, B - view of the left bank 


\section{Results and discussion}

Both macroscopic and microscopic features of river sediments were examined. In the field a typical horizontal bedding, underlined with color changes and fractional diversification of deposited sands. In the bottom part of the profile thin lenses of fine sands were observed, as well as, some organic relics of wood particles and crushed shells. The most of sediments are composed of yellow medium and coarse sands, partly interbedded with gray color inclusions in the base. Laboratory analysis confirmed the domination of fine sandy fraction $(69 \%)$ with $11 \%$ of medium and $13 \%$ of coarse sands. Up to $7 \%$ of particles finer than sand and the presented grain size distribution is pointing at balanced deposition conditions at water velocities below 0.2 $\mathrm{ms}^{-1}$. No erosional discontinuities were observed. The determination of some basic geochemical properties showed the values of $\mathrm{pH} 7.70$ and 7.75 in $\mathrm{H}_{2} \mathrm{O}$ and $\mathrm{KCl}$, which is a normal value, along with low conductivity $\left(364 \mu \mathrm{Scm}^{-1}\right)$ testifying relatively good water quality, not influencing the precipitation of soluble contaminants. Hydrochloric acid tests showed $\mathrm{CaCO}_{3}$ content below the detection level.

Micromorphological analysis of the thin section prepared from Vistula river channel deposits allowed more precise possibility to assess spatial distribution of components in relation to free spaces and determination of grains shapes and frequencies of their appearance. Analyzing the surface of the $2.5 \times 4.5 \mathrm{~cm}$ thin section image the fractional bedding was observed (Fig. 4). The basic mass is composed of medium and fine sands, separated with a threshold layer of thicker sediment. Unordered, darker laminae in the bottom part of the slide are remnants of an organic component, most probably wood, and poorly sorted quartz grains, covered with an episodic sediments layer, represent a sudden change of flow velocity, probably caused by increased rainfall in June 2012 .

The whole sequence is divided into four distinct parts. From the bottom grains are poorly sorted, compacted, with larger quartz grains (Fig. 5A) and wood fragments in-washed in the form of laminae (Fig. 5B). Second segment is characterized by the appearance of fine sands accompanied with smaller fractions (Fig. 5C) ant the third reveal large amount of free spaces between coarser, medium-sorted particles (Fig. 5D). The final stage of deposition is composed of medium and fine sands mixture (Fig. $5 \mathrm{E})$. Interpretation of sedimentary environment from energetic point of view is showing considerable changes of flow regime on centimeter scale, normally not detected with bulk sampling. Segments I and III are characterized by poorly sorted material, transported and deposited in conditions of quick change of depositional environment, additionally supplied at the bottom with water level drop, leading to precipitation of floating organic material. Stable, slow motion discharge is recorded in segments II and IV, where well sorted and finer deposits are accumulated.

\section{Conclusions}

The use of micromorphological methods in the analysis of Vistula river channel deposits allow not only to confirm macroscopic observations, but also to add new premises

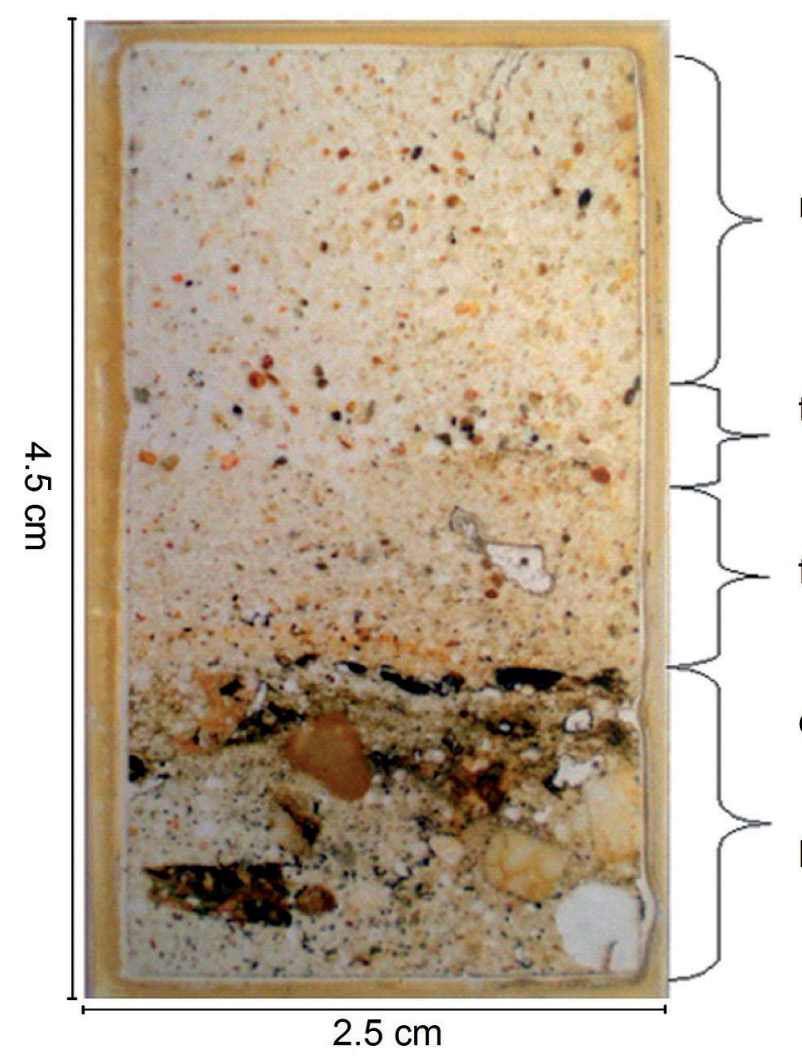

medium sands

thicker border deposits

fine sands

dark, unordered laminae, remnants of some organic component

poorly sorted quartz grains covered with episodic layer of deposits and single granular laminae

Fig. 4. Lithologic description of sediments in the thin section 

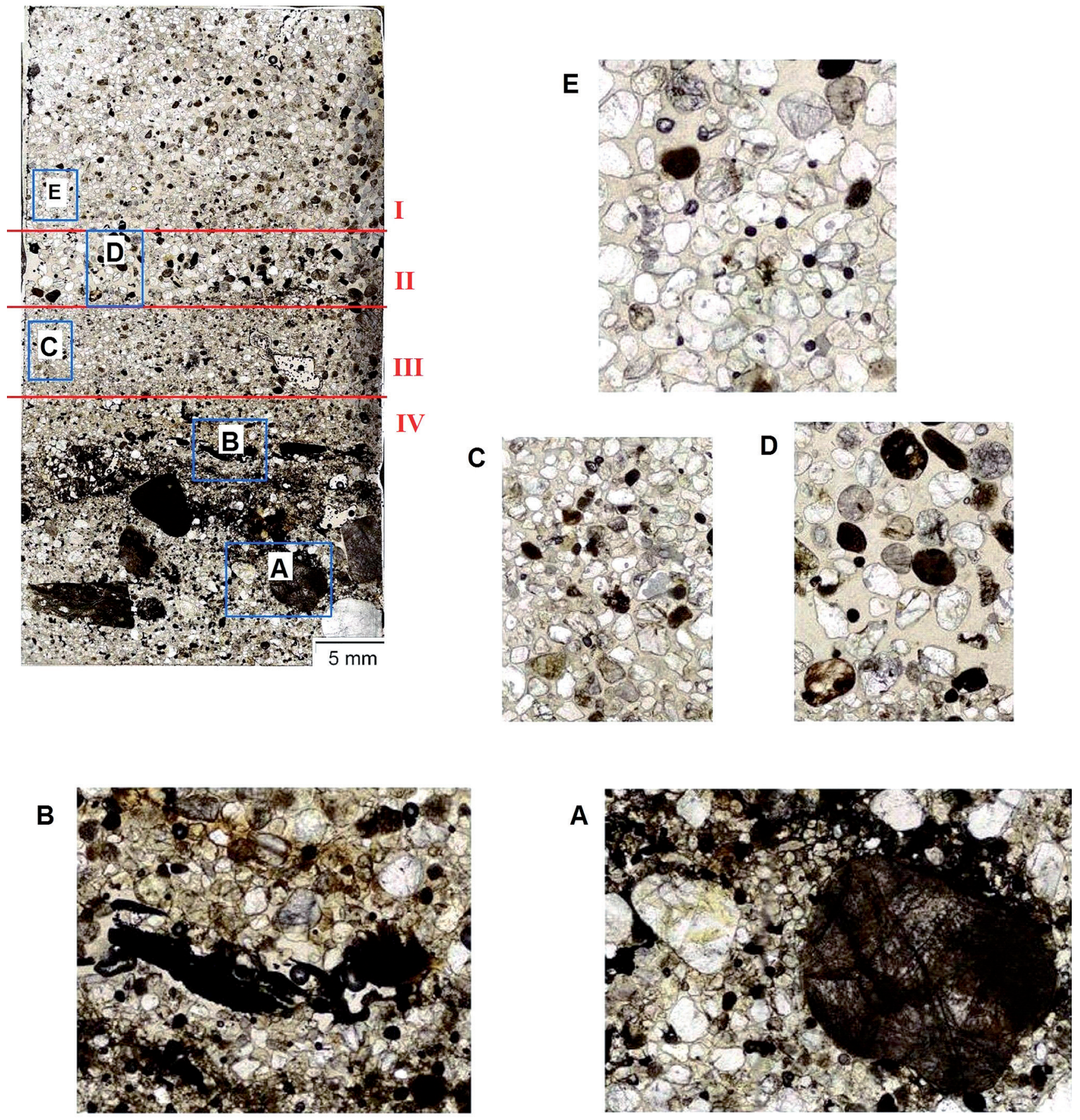

Fig. 5. Sediments thin section details

A - poorly sorted, compacted sediments, B - fine sediments with laminations, $\mathrm{C}$ - fine sediments, D - coarse grains with empty spaces between, $\mathrm{E}-$ medium grain sediments

on environmental condition changes. In the $2.5 \times 4.5 \mathrm{~cm}$ slide it is possible to distinguish between even very slight variations in discharge dynamics through the observations of grain size, grain shape, sorting, character of deposited particles and structure. The presented thin section is a record of two separate impulses of water flow, varying additionally in terms of channel bar surface exposition. The application of micromorphological method is offering wide future prospects e.g. in terms of analyzing microstructures on the level of separate grains associations, however, because of its complication and time-consuming procedures, can be used to solve only specific problems.

\section{References}

Brewer R., 1964. Fabric and mineral analysis of soil. John Wiley and Sons. New York.

Budek A., 2010. Zastosowanie analizy mikromorfologicznej w badaniach gleb i osadów czwartorzędowych. Landform Analysis 12: 23-30.

Bullock P., Fedorof N., Jongerius A., Stoops G., Tursina T., 1985. Handbook for soil thin section description. Wine Research Publication.

Cailleau G., Verrecchia E.P., Braissant O., Emmanuel L. 2009. The biogenic origin of needle fibre calcite. Sedimentology 56: 1858-1875.

Camuti K.P., McGuire P., 1999. Preparation of polished thin sections from poorly consolidated regolith and sediment materials. Sedimentary Geology 128: 171-178. 
Carr S.J., 2004. Micro-scale features and structures. In: D.J.A.Evans, D.I.Benn (eds), A practical guide to the study of glacial sediments. Arnold. London: 115-144.

Douglas L.A. (eds), 1988. Soil Micromorphology: A Basic and Applied Science. Proceedings of the International Working Meeting on Soil Micromorphology. Developments in Soil Science 19: 581-603.

Fitzpartick E.A., 1993. Soil Microscopy and Micromorphology. Willey. New York

Kemp R.A., 1985. Soil micromorphology and the Quaternary. Quaternary Research Association Technical Guide 2, Cambridge.

Kemp R.A., 1998. Role of micromorphology in peleopedological research. Quaternary International 51/52: 133-141.

Kołodziej G., 1995. Petroskop - nowe możliwości prezentacji wizualnej. Przegląd Geologiczny 43: 952-953.

Konecka-Betley K., 1996. Zastosowanie metody mikromorfologicznej do badań gleb kopalnych. W: Materiały Konferencyjne. Metody badań paleopedologicznych i wykorzystanie gleb kopalnych w paleogeografii. Łódź, 26-28 czerwca 1996: 19-20.

Kubiena W.L., 1938. Micropedology. Collegiate Press. Ames. Iowa.

Lee J., Kemp R., 1992. Thin sections of unconsolidated sediments and soils: a recipe. Centre for Environmental Analysis and Management
(CEAM). Royal Holloway, University of London. CEAM Technical Report 2.

Menzies J., Van der Meer J.J.M., Domack E., Wellner J.S., 2010. Micromorphology: as a tool in the detection, analyses and interpretation of (glacial) sediments and man-made materials. Proceedings of the Geologists' Association 121: 281-292.

Mroczek P., 2001. Mikromorfologia osadów klastycznych i gleb. Przedmiot, zastosowanie i wybrane metody analiz. Czasopismo Geograficzne 72(2): 211-229.

Murphy C.P., 1986. Thin Section Preparation of Soils and Sediments. AB Academic Publishers, Berkhamsted.

Stoops G., 2003. Guidelines for analysis and de scription of soil and regolith thin section. Soil Science Society of America, Inc. Madison Wisconsin.

Palmer A.P., Lee J.A., Kemp R.A. \& Carr S.J., 2008. Revised laboratory procedures for the preparation of thin sections from unconsolidated material. Unpublished internal report. Royal Holloway. University of London.

Pusch R., 1999. Experience from preparation and investigation of clay microstructure. Engineering Geology 54: 187-194.

Van der Meer J.J.M., Menzies J., 2011. The micromorphology of unconsolidated sediments. Sedimentary Geology 238: 213-232. 